\title{
THE ACQUISITION OF RECURSIVELY EMBEDDED NOUN MODIFIERS IN ROMANIAN BY HUNGARIAN-ROMANIAN BILINGUALS
}

\author{
Larisa Avram, Anca Sevcenco \& Veronica Tomescu*
}

\begin{abstract}
The present study examines how simultaneous bilinguals acquire phenomena which are delayed in monolingual development. It compares how 5- and 7-year-old Hungarian-Romanian bilinguals and Romanian monolinguals comprehend complex DPs with recursively embedded locative Prepositional Phrase and subject relative clause modifiers. The order of acquisition is the same in L1 and in 2L1: during the early stages children assign both conjunctive and recursive readings to complex DPs with embedded modifiers and gradually reduce the number of conjunctive responses to the advantage of recursive ones. At age 7 neither the monolinguals nor the bilinguals behave adult-like. But the results reveal a significant increase in recursive responses from age 5 to age 7 only in L1. In $2 \mathrm{~L} 1$, at this stage, there is an increase only in the number of conjunctive responses and in errors which target the lexical preposition. Our findings show that the simultaneous bilinguals follow the same acquisition path as the monolinguals but at a slower pace. We argue that when a derivationally complex structure is vulnerable in L1 acquisition, cross-linguistic interference effects may cause an even more prolonged delay in $2 \mathrm{~L} 1$ acquisition.
\end{abstract}

Keywords: recursive, noun modifier, prepositional phrase, relative clause, Hungarian-Romanian bilinguals

\section{Introduction}

Recent studies on the production and comprehension of recursively embedded nominal modifiers have revealed that these structures are mastered late in L1 acquisition (Pérez-Leroux et al. 2012, Sevcenco et al. 2017, Tóth et al. 2016, Terunuma et al. 2017, Tóth 2017, Sevcenco \& Avram 2018). At first sight, this result is unexpected. Recursion is a core property of human language (Hauser et al. 2002, Chomsky 2013) and the acquisition of complex DPs involves narrow syntactic phenomena, which are the first to emerge in L1. Core syntax is also acquired early by simultaneous bilinguals (Tsimpli 2014). Therefore the cause of the delay in the acquisition of recursively embedded nominal modifiers in both L1 and 2L1 should be searched outside narrow syntax, "at the interaction between universal principles of language and considerations not specific to language" (Roberge et al. 2018). What children have to acquire are the specific properties of recursive structures. Another important finding is that the acquisition path is the same across languages: (i) structures with one-level embedding are acquired before those with multiple embedding, and (ii) children first assign a conjunctive interpretation to recursive nominal modifiers (the dog that is on the cat (and) that is on the chicken); the recursive interpretation is attested later (Sevcenco et al. 2017, Tóth 2017, Sevcenco \& Avram 2018). But recursive structures are not acquired concurrently (Pérez-Leroux et al. 2012,

\footnotetext{
*University of Bucharest larisa.avram@lls.unibuc.ro, anca.sevcenco@g.unibuc.ro, veronica.tomescu@lls.unibuc.ro. The authors contributed equally to this paper. They are listed in alphabetical order.

Previous versions of this paper were presented at Workshop on Computational Complexity in Language Acquisition, University of Cambridge, November 29, 2016, GALA 13 (Palma de Mallorca, September 7-9, 2017), $2^{\text {nd }}$ International Conference on Bilingualism, 7-9 September 2017, Palma de Mallorca. We thank the audiences for their challenging and helpful questions and suggestions.
}

Bucharest Working Papers in Linguistics XXII, 1, 61-84, e-ISSN 2392-8093, ISSN-L 2069-9239 DOI: 10.31178/BWPL.22.1.4 
Terunuma et al. 2017), i.e. their linguistic properties can determine the timing of language development.

Previous studies focused mainly on monolingual development. The investigation of the acquisition of recursively embedded structures in a $2 \mathrm{~L} 1$ context is only at its beginning (but see Pettibone et al. 2016, Pérez-Leroux et al. 2017). The few available results suggest that bilingual children lag behind only in the acquisition of one-level embedding structures. They have been accounted for in terms of knowledge of functional vocabulary, a hypothesis which straightforwardly predicts cross-linguistic variation, given the fact that the properties of functional vocabulary are language-specific. It also predicts a general delay in the acquisition of recursively embedded noun modification which involves specific lexical knowledge, with low input frequency possibly playing an important part. And, since the input which bilingual children receive is limited in comparison with the input in monolingual acquisition, one would expect these structures to be even more delayed in $2 \mathrm{~L} 1$. This is why investigating the acquisition of recursively embedded modified structures by bilingual children in a larger number of languages and language pairs can shed light on the interplay between the core property of human language, recursion (Hauser et al. 2002), language specific properties and dual linguistic input.

Our study extends the investigation to the acquisition of complex noun modification in a simultaneous bilingual context (2L1). We focus on the comprehension of recursive nominal modifiers, locative PPs and subject relative clauses in Romanian by 5- and 7-year-old Romanian-Hungarian bilingual children.

The remainder of this paper is organized as follows: in section 2 we offer a brief description of the main properties of recursive locative PP and relative clause noun modifiers in Romanian and Hungarian. In section 3 we summarize the main findings of previous studies on the L1 acquisition of these structures, with a focus on L1 Romanian and L1 Hungarian. Section 4 presents the study and its main findings. Our results reveal that Hungarian-Romanian bilinguals follow the same steps in the acquisition of recursively embedded noun modifiers as Romanian monolinguals but at a slower pace. The delay is accounted for in terms of cross-linguistic interference effects. Section 5 concludes.

\section{Recursively embedded noun modifiers in Romanian and Hungarian}

\subsection{Romanian}

Romanian has post-nominal prepositional and relative clause modifiers. Recursion in the locative PP domain is overtly marked by a functional preposition, de 'of', whose presence is obligatory, and which precedes the lexical preposition denoting location (Giurgea 2015). Lexical prepositions (with the exception of $c u$ 'with') ban DP complements with an overt definite article. For example, pe 'on' in (1) can only be followed by a DP without the definite article. The presence of the enclitic definite article on the noun in (2a) renders the sentence ungrammatical. But if the DP is further modified (as in $2 b$ ), the presence of an overt article is obligatory: 
casa $\quad *($ de $)$ pe deal

house-the of on hill

'the house on the hill'
a. casa de pe *dealul
house-the of on hill-the
'the house on the hill'
b. casa de pe deal*(ul) din faţă
house-the of on hill the from front
'the house on the hill in front of us'

In complex DPs with recursive PP modification, definiteness plays a disambiguating role. If the modified noun occurs with a definite article, the only possible interpretation is the recursive one. In (3), for example, the noun inside the first PP modifier is definite, pădurea 'forest-the'. In this case, the second PP modifier, de pe deal 'on the hill', can only be interpreted as modifying the nominal inside the previous PP (see 3). But if the DP is headed by an indefinite article, both a recursive and a conjunctive interpretation (as shown in 4) are allowed:

$$
\begin{aligned}
& \text { casa de lângă pădurea de pe deal } \\
& \text { house-the of near forest-the of on hill } \\
& \text { 'the house next to the forest on the hill' } \\
& \text { casa de lângă o pădure de pe deal } \\
& \text { house-the of near a forest of on hill }
\end{aligned}
$$

(i) 'the house next to a forest on a hill'

(ii) 'the house next to a forest and a hill'

Therefore, PP modification offers two cues for recursive interpretation: an overt marker of recursion (the functional preposition $d e$ 'of') and definiteness on the modified noun.

Full relative clauses are introduced by the relative pronoun care 'who/which', i.e. modification with subject relatives has an overt marker of recursion, on a par with PP modification. Just as in the case of PP modification, definiteness affects the interpretation of these complex structures. If the noun modified by a relative clause occurs with the definite article, the recursive reading obtains (as in 5):

casa care este lângă pădurea care este pe deal house-the that is near forest-the that is on hill 'the house that is next to the forest that is on the hill'

If the noun modified by a relative clause occurs with an indefinite article, the structure is ambiguous between a recursive and a conjunctive interpretation (6):

casa care e lângă o pădure care este pe deal house-the that is near a forest that is on hill

(i) 'the house that is next to a forest that is on the hill'

(ii) 'the house that is next to a forest and on the hill' 
As can be seen in the examples above, in Romanian both PP and relative clause nominal modification is uniformly right-branching.

\subsection{Hungarian}

Hungarian has (i) embedded postpositional phrases adjectivized by the suffix $-i$ (as in 7a), and (ii) embedded postpositional phrases in levö participial structures (as in 7b) (Tóth et al. 2016):

$$
\begin{aligned}
& \text { a. egy disznó mellett-i ló mellett-i csirke } \\
& \text { a pig near ADJ horse near ADJ chicken } \\
& \text { 'a chicken next to a horse next to a pig' } \\
& \text { b. egy lo -von levő macská-n levő disznó } \\
& \text { a horse on being-PRT cat on being-PRT pig } \\
& \text { 'a pig on a cat on a horse' }
\end{aligned}
$$

Recursively embedded modification in the relative clause domain is rendered by mixed syntactic structures that involve (i) a postnominal finite relative clause and prenominal participial structures (illustrated in 8 a) or (ii) a postnominal finite relative clause and embedded postpositional phrases adjectivized by $-i$ (illustrated in $8 b$ ):
a.
egy macska amelyik egy disznó-n levő lo -von van a cat which a pig on being-PRT horse on is 'a cat that is on a horse that is on a pig'
b. egy disznó amelyik a macska mellett-i csirke mellett van a pig which the cat near ADJ chicken near is 'the pig that is next to the chicken that is next to the cat'

Both Romanian and Hungarian have overt recursion markers. But the recursive structures under investigation differ with respect to directionality and word order.

\section{Recursive noun modifiers in acquisition}

Recursive embedding is a core property of language, which should emerge from the onset of language acquisition. The literature offers strong evidence that children acquire core syntax early. But a growing number of studies have been revealing that recursive nominal modifiers are neither produced nor comprehended adult-like until school years (Limbach \& Adone 2010, Pérez-Leroux et al. 2012, Tóth et al. 2016, Sevcenco \& Avram 2016, 2018, Tóth 2017, Terunuma et al. 2017). They also show that the acquisition route uniformly goes from direct recursion (i.e. conjunction) to indirect recursion (Roeper 2011) and from one-level embeddings to structures with multiple embeddings.

English-speaking children follow a developmental path which goes from structures with one modifier (see, for example, Alegre \& Gordon 1996) to conjunctive structures 
and only after age 5;7 to recursive ones (Limbach \& Adone 2010). Pérez-Leroux et al. (2012) tested three groups of English-speaking children (mean ages 3;2, 4;4 and 5;2) on the production of coordinated nominals, recursive possessives and recursive PPs. Their results reveal that coordinated structures are produced earlier than recursive ones, single level embeddings before recursive embeddings and multiple recursive PPs before multiple (double) possessors. Interestingly, Roberge et al. (2018) compare the English data in Pérez-Leroux et al. (2012) to data from child French. No developmental difference with respect to recursive complex DPs has been found, in spite of the differences between recursive modification in these two languages.

The picture which emerges from Sevcenco et al. (2017) is similar. These authors show that before age 6 English-speaking children preferentially assign conjunctive readings to recursive structures. Just like the data in Pérez-Leroux et al. (2012), theirs also reveal that recursive structures are not equally vulnerable. They tested the comprehension of PP and relative clause noun modifiers. The results indicate that English-speaking children acquire relative clause noun modification earlier than PP noun modification. These findings are accounted for in terms of the nature of the functional marker: overt with relative clauses and covert with PP recursion. Alternatively, they suggest that the data could be interpreted as indicative of an acquisition advantage of recursion in the full clausal domain.

The data described in section 2 show that in both Romanian and Hungarian there are overt functional markers of recursion. In principle, if the nature of the functional marker determined the acquisition route of complex DPs with recursively embedded modifiers, as suggested in Sevcenco et al. (2017), one would predict early acquisition of recursive noun modification in these two languages. However, the few available acquisition studies on recursive configurations in child Romanian and child Hungarian report results which reveal a delay in the acquisition of complex DPs with recursively embedded modifiers. Children interpret recursive sequences as conjunctive first and move on to the recursive reading only after age 7 , in spite of the fact that the functional marker of recursion is overt. In Hungarian, children attain adult-like knowledge of recursive modifiers only at age 9 (Tóth et al. 2016). As shown in section 2, in Hungarian recursive nominal modification may be obtained by combining the suffix $-i$ with a preposition, thus turning the preposition into an adjectivized form or by using the present participle of the verb be (levó). The latter is more salient (lexically, phonologically and semantically). This difference in saliency is reflected in differences in acquisition. The 7-year-old children in Tóth et al.'s (2016) study assigned a recursive interpretation to the structures with levö more frequently. But, in Tóth (2017), no significant difference was found between the response pattern to test items with embedded postpositional phrases adjectivized by the suffix $-i$ (illustrated in $7 \mathrm{a}$ ) and those with embedded postpositional phrases in levö participial structures (illustrated in 7b).

At age 5, in an act-out task, Romanian monolinguals randomly assign a recursive or a conjunctive interpretation to recursively embedded noun modifiers (PP and subject relative clause, illustrated in 3 and 5 above) (Sevcenco \& Avram 2016, 2018), though both have an overt functional marker. No developmental advantage for clausal domains has been attested. In a more recent study, however, Bleotu (2020) shows that when a colouring task or a picture-matching task is used, the rate of recursive responses of 
5-year-old Romanian monolinguals improves significantly. But her results also confirm that the conjunctive reading is the default one.

To sum up, available data from L1 studies provide evidence that children start with the conjunctive interpretation, the default option, and acquire recursive nominal modifiers late (Roeper 2011: 65). Younger children prefer a less complex nominal modification structure. This preference has been explained in terms of computational load, which is a manifestation of third factor effects of the type "less is better than more" (Chomsky 2014: 5). According to Sevcenco \& Avram (2018), opting for the conjunctive interpretation possibly represents an attempt at integrating the required adjuncts in the overall configuration such as to avoid a second embedding across intermediate phasal domains, i.e. children avoid multiple embedding relationships.

Besides computational overload, the delay has also been discussed in relation to performance limitations, the difficulty of matching syntax and semantics across phasal domains and 'intermediate domains of reference' when introducing several levels of embedding (Pérez-Leroux et al. 2015). Some studies also mentioned possible task effects, such as processing memory load (Bleotu 2020) or reduced frequency in the input.

As mentioned earlier, not many studies looked into the acquisition of recursive configurations by bilinguals. Though $2 \mathrm{~L} 1$ generally follows the same route as L1 acquisition (Meisel 1989, 2011, Paradis \& Genesee 1996), many studies have revealed possible areas of vulnerability. The inventory of sources of bilingual delay includes bilingualism per se, computational complexity, relatively reduced input (Pîrvulescu et al. 2014), cross-linguistic interference effects, or language dominance. The growth of vocabulary has also been standardly assumed to lag behind in bilinguals (Bialystok 2009; but see Müller 2017 for evidence against this point of view) with possible effects on the acquisition of grammar phenomena which require specific lexical knowledge (Unsworth 2014). This is, for example, the case of PP noun modifiers. Pérez-Leroux et al. (2017) offer data which show that Spanish-English bilinguals (age range 4;00-6;11) lag behind age-matched English monolinguals but the delay is more significant with respect to the production of PP modification with one level of embedding. No delay was found with respect to recursive modification, i.e. not with the second embedding in the derivation of recursively modified nouns. Once the embedding rule has been acquired, recursive structures are also acquired. The authors account for this difference in terms of what they call the lexically-dependent vulnerability hypothesis. The observed delay does not target the recursive structure per se but knowledge of functional vocabulary and of embedding rules. What is actually delayed is lexical learning.

\section{The study}

\subsection{The questions}

The aim of the present study is to investigate the acquisition of recursively embedded PP and relative clause noun modifiers in 2L1 Romanian by HungarianRomanian bilinguals. The first question which we address is whether the acquisition route 
of recursively embedded noun modifiers proceeds along the same steps and at similar speed in 2L1 Romanian in a Hungarian-Romanian bilingual setting as in L1 Romanian.

According to the unitary language system hypothesis (Meisel 1989, 2011, de Houwer 1990) acquisition proceeds in the same way in L1 and in 2L1; the grammatical competence of simultaneous bilingual children is the same as in monolingual children. On this view, one would predict that the acquisition of recursively embedded PP and relative clause noun modifiers should follow the same route and proceed within the same time frame in $\mathrm{L} 1$ and in $2 \mathrm{~L} 1$.

Previous studies, however, have shown that recursive embedding is acquired later in $2 \mathrm{~L} 1$ when the embedding rule involves lexical learning (Pérez-Leroux et al. 2017) and, consequently, requires more exposure to input. Generally, those language properties whose learning is more input sensitive, as seems to be the case with recursive modification, are acquired relatively later in L1, are less stable in language contact situations and hence more likely to be affected by cross-linguistic interference in $2 \mathrm{~L} 1$.

The second question which we address is whether the acquisition of recursively embedded noun modifiers by Romanian-Hungarian bilinguals reflects cross-linguistic interference effects. We saw that both Hungarian and Romanian have overt markers of recursion. But the word order within complex DPs with recursively embedded modifiers is also different. In Romanian, nominal modification is uniformly right-branching. In Hungarian, word-order differs in complex DPs with PP and relative clause modifiers. Relative clauses are to the right of the modified noun; adjectivized and participial PPs occur to the left. Within DPs with (mixed) relative clause structures, inside the modification domain the order is similar to the one inside DPs with participial PPs. It is plausible to predict that different word order can result in cross-linguistic effects. Additionally, if one assumes that computational complexity favours cross-linguistic interference effects, the derivational complexity associated with recursively embedded noun modifiers would also predict cross-linguistic interference.

\subsection{Participants}

The Hungarian-Romanian bilinguals who took part in our study come from Hungarian-Romanian or Hungarian families. They are all simultaneous bilinguals. They speak Hungarian at home with at least one parent. They live in Bucharest, where the language of the community is Romanian. But they attend a Hungarian kindergarten or school, where they spend approximately 8 hours per day and where Hungarian is practically the only language used for both communication and instruction.

32 Hungarian-Romanian bilingual children took part in the study. They were divided in two age groups: 16 5-year-olds (mean 5;1, SD: .55) and 16 7-year-olds (mean 7;4, SD: .60). Their responses were compared to those of a group of age-matched Romanian monolinguals, all living in Bucharest. They were similarly divided into two age groups: a group of 16 5-year-olds (mean 5;2, SD: 54) and a group of 16 7-year-olds (mean: 7;3, SD: .53). The results from 10 Romanian adults (mean age 35;3) (also reported in Sevcenco \& Avram 2018) were also used in the analysis. 


\subsection{Task}

We used an act-out task with Explain Everything, presented on iPad support, an adaptation of the task originally designed for English by Sevcenco et al. (2017) and previously used for Romanian in Sevcenco \& Avram (2016, 2018). In the warm-up part, the experimenter showed the participant that the animals could be moved on the screen and arranged as one wanted to. In the testing part, the participants were required to arrange the animals in various arrays on the iPad, so that the resulting image should correspond to the prompt given by the researcher, e.g. Show me the dog next to the cat next to the horse.

Five pictures of animals familiar to children (horse, pig, dog, cat, and chicken) were used in the task. The animals were always shown in a fixed position on the display before the prompt was given (as in Figure 1):

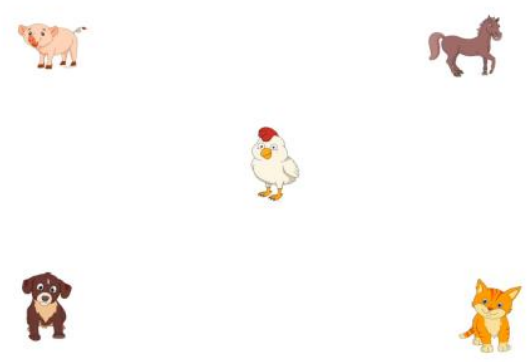

Figure 1. Display before the prompt was given

The child could hear each test item up to three times if necessary. Children were tested individually, at their kindergarten or school, in a quiet room.

The test included two conditions: recursive PP and subject relative clause noun modifiers with double embedding. Each condition had 8 test items, balanced for definiteness (see the Appendix at the end of the paper for the complete list of test sentences).

The test item in (9) illustrates recursively embedded PP noun modifiers. The second modified noun has an overt definite article. This structure, as shown in section 2.1 , allows only the recursive interpretation.

Arată-mi pisica de lângă calul de lângă pui. show me cat-the of near horse-the of near chicken 'Show me the cat next to the horse next to the chicken.'

The test item illustrated in (10) is ambiguous: it can be assigned a recursive or a conjunctive interpretation. The second modified noun is preceded by the indefinite article.

Arată-mi un pui de lângă un cal de lângă un porc.

show me a chicken of near a horse of near a pig

'Show me a chicken next to a horse next to a pig.' 
The sentences in (11) and (12) illustrate test items with recursively embedded relative clauses. In (11) the second modified noun occurs with the definite article and, just like in (9) above, the only interpretation is the recursive one. In (12) the second modified noun (underlined for convenience) is preceded by the indefinite article. This structure is ambiguous, allowing both a recursive and a conjunctive reading.

$$
\begin{aligned}
& \text { Arată-mi calul care este lângă pisica care este lângă porc. } \\
& \text { show me horse-the that is near cat-the that is near pig } \\
& \text { 'Show me the horse that is next to the cat that is next to the pig.' } \\
& \text { Arată-mi un cal care este pe un porc care este pe un pui. } \\
& \text { show me a horse that is on a pig that is on a chicken } \\
& \text { 'Show me the horse that is on a pig that is on chicken'. }
\end{aligned}
$$

\subsection{Coding}

The responses were coded as: (i) recursive; (ii) conjunctive; (iii) other; (iv) preposition error. An answer was coded as recursive when the array for a prompt like Show me the pig next to the chicken next to the cat looked like the one in Figure 2:

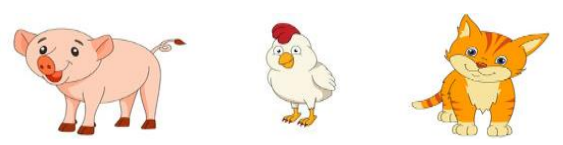

Figure 2. Example of a recursive response to Show me the pig next to the chicken next to the cat.

This answer was analyzed as corresponding to the structure: [DP $\mathrm{N}[\mathrm{PP} \ldots \mathrm{N}[\mathrm{pP} \ldots \mathrm{N}]]]$. The response was coded as conjunctive when, at a prompt like Show me the cat next to the pig next to the chicken, for example, the participant created an array in which the cat appeared in between the pig and the chicken, as in Figure 3:
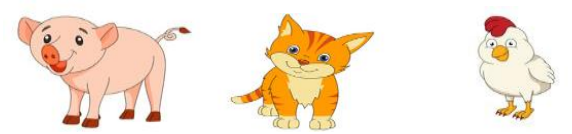

Figure 3. Example of a conjunctive response to Show me the cat next to the pig next to the chicken.

For test items with on, the array presented one animal above other two.

The category "other" included random arrays with two or four animals or the required three animals arranged in a set-up that did not correspond to the prompt. In response to, for example, Show me the cat next to the pig next to the chicken, an "other" array could look like the one in Figure 4:

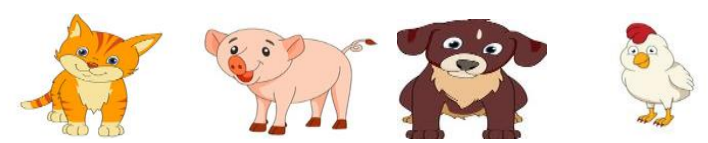

Figure 4. Example of an "other" response to Show me the cat next to the pig next to the chicken 
Some answers were coded as preposition errors. For example, if in response to Show me the cat on the pig on the chicken, the participant gave the array in Figure 5, it was analyzed as a recursive response in which on was mistakenly interpreted as under.

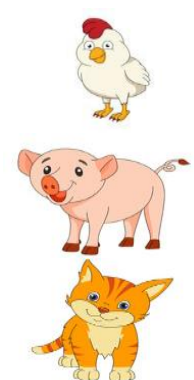

Figure 5. Example of a preposition error response to Show me the cat on the pig on the chicken.

\subsection{Results}

\subsubsection{Recursive responses}

We first examined the overall frequencies of recursive responses. Adults gave recursive interpretation at a very high rate $(94 \%)$. Overall, the 5-year-old bilinguals responded with recursive arrays $44.53 \%(\mathrm{n}=114)$ of the time and the 5-year-old monolinguals only $39.1 \%(\mathrm{n}=100)$. The 7-year-old bilinguals gave $44.14 \%(\mathrm{n}=113)$ and the 7-year-old monolinguals $63.3 \%(\mathrm{n}=162)$ recursive responses.

The results are summarized in Table 1.

Table 1. Overall recursive answers (mean and SD) across groups

\begin{tabular}{ccc} 
Age group & L1/2L1 & Overall /16 \\
5-year-olds & 2L1 & $7.13(3.05)$ \\
\cline { 2 - 3 } 7-year-olds & L1 & $6.25(3.02)$ \\
& L1 & $7.1(3.96)$ \\
Adults & & $10.13(3.96)$ \\
& & $15.16(.99)$
\end{tabular}

In order to test whether the difference between the four groups was significant, a one-way ANOVA was conducted; the analysis of variance revealed that the difference between the recursive responses given by the four groups was significant: $F(3,60)=3.22$, $p=.02$. Post-hoc tests with Bonferroni correction showed that the 5-year-old bilinguals performed like the 5-year-old monolinguals. But the difference between the 5-year-old and the 7-year-old monolinguals reaches significance $(p<.012)$. The 7-year-old monolinguals gave significantly more recursive responses than the 5-year-olds. No age effect was found with the bilingual children; the 7-year-old bilinguals behaved like the 5 -year-old ones. 
The results of a series of one-sample t-tests which investigated whether the mean of recursive responses for each group was statistically above chance $\left(33 \%{ }^{1}\right)$ support this conclusion. The 5-year-old monolinguals' scores were not significantly above chance $(p>.05)$ whereas those of the 7-year-olds were $(p<.05)$. Unexpectedly, with the bilinguals, the scores were above chance only with the 5-year-olds.

The analysis of individual performance also suggests that the 7-year-old monolinguals are the most 'advanced' group. It is only in this group that some children gave recursive responses $100 \%(n=16)(4$ children). In the group of 7-year-old bilinguals the highest score was 13 (out of 16), and it was attested with only one participant.

\subsubsection{Recursive interpretation of DPs with PP and relative clause modifiers}

The next step in our analysis was to compare the rate of recursive responses per condition: PP and relative clause modifiers. Adults gave a recursive interpretation in $91.7 \%$ of cases in the PP condition and in $98 \%$ of cases in the relative clause condition.

The 5-year-old bilinguals assigned a recursive interpretation $43 \%(\mathrm{n}=55)$ in the PP condition and $46.1 \%(n=59)$ in the relative clause condition. Their results are similar to those of the monolingual group: $36.7 \%(n=47)$ in the PP condition and $41.4 \%(n=53)$ in the relative clause condition. They are summarized in Table 2.

Table 2. Recursive answers (mean and SD) in the PP and relative clause conditions

$\begin{array}{cccc}\text { Group } & \text { Age } & \text { PP /8 } & \text { Relative clause /8 } \\ \text { 5-year-olds } & \text { 2L1 } & 3.5(2.13) & 3.7(1.35) \\ & \text { L1 } & 2.9(1.57) & 3.3(1.96) \\ \text { 7-year-olds } & \text { 2L1 } & 3.5(1.86) & 3.6(2.34) \\ & \text { L1 } & 5.1(2.69) & 5.1(2.69) \\ \text { Adults } & & 7.33(.81) & 7.83(.41)\end{array}$

A two-way ANOVA was conducted on the effect of group and condition on the number of recursive responses. There was no significant main effect of group, $\mathrm{F}(1,60)=$ $0.99, p>.05$. There was no main effect of condition $(\mathrm{F}(1,60)=0.49, p>.05)$ and no significant interaction between group and condition $(\mathrm{F}(1,60)=0.02, p>.05)$, i.e. the difference between the number of responses (in both conditions) given by the 5 -year-old bilinguals and the number of recursive responses given by the 5-year-old monolinguals was not significant.

The 7-year-old bilinguals did not treat relative clause and PP modifiers differently either. They assigned a recursive interpretation to complex DPs with recursively embedded PP modifiers $43.8 \%(n=56)$ of the time and to complex DPs with embedded relative clause modifiers $44.5 \%(n=57)$ of the time. Their results are below those of the monolingual group who gave $63.3 \%(\mathrm{n}=81)$ recursive answers in both conditions. A two-way ANOVA revealed a significant main effect for group, $\mathrm{F}(1,60)=6.95, p<.05$, i.e. the 7-year-old bilinguals gave a significantly lower number of recursive responses than the 7-year-old monolinguals. There was no main effect of condition $(\mathrm{F}(1,60)=$ $0.003, p>.05)$ and no significant interaction between group and condition $(\mathrm{F}(1,60)=$ $0.003, p>.05)$, i.e. neither group treated PP and relative clause modification differently.

\footnotetext{
${ }^{1}$ The participants could provide three response types: recursive, conjunctive and "other".
} 


\subsubsection{Recursive responses and definiteness}

We then compared the Romanian-speaking children's sensitivity to definiteness in determining a recursive reading. Neither the $2 \mathrm{~L} 1$ groups nor the monolingual ones showed sensitivity to definiteness in any of the two conditions. Adults gave a recursive interpretation in $93.75 \%$ of the cases when the (second) modified noun occurred with the definite article and 95.83\% when it occurred with an indefinite article overall (PP and RC modification). The 5-year-old bilinguals assigned a recursive interpretation $46.1 \%$ $(\mathrm{n}=59)$ to DPs when the modified nominal was definite and $43 \%(\mathrm{n}=55)$ when it was indefinite. The results of the 5-year-old monolinguals were similar. They responded with recursive arrays $39.1 \%(n=50)$ both when the modified nominal was definite and when it was indefinite.

A mixed ANOVA with condition (PP definite, PP indefinite, relative clause definite, relative clause indefinite) as within-subjects variable and group (2L1 and L1) as between-subjects factor was conducted for the 5-year-old groups. The results revealed no main effect of condition, $\mathrm{F}(3,90)=.431, p>.05$. There was no significant interaction between group and condition either, $\mathrm{F}(3,90)=.274, p<.05$, which indicates that the 5 -year-old bilinguals performed like the 5-year-old monolinguals in this respect. Both groups failed to rely on definiteness as a cue to recursive readings. The 7-year-old bilinguals responded, across conditions, with recursive arrays $43.5 \%(n=53)$ when the modified nominal was definite and $46.1 \%(n=60)$ when it was indefinite. The 7-year-old monolinguals did not assign more recursive interpretations to DPs with a definite modified noun either. They gave $61.8 \%(n=79)$ responses when the second modified noun was definite and $64.8 \%(\mathrm{n}=83)$ when it was indefinite.

A mixed ANOVA with condition (PP definite, PP indefinite, relative clause definite, relative clause indefinite) as within-subjects variable and group (2L1 and L1) as between-subjects factor was conducted for the 7-year-old groups. The results confirmed no main effect of condition, $\mathrm{F}(3,90)=.926, p>.05$. There was no significant interaction between group and condition either, $\mathrm{F}(3,90)=.078, p>.05$; the bilinguals performed like the monolinguals with respect to definiteness as a possible cue of recursive structure.

Table 3 summarizes the results with respect to the role of definiteness.

Table 3. Recursive responses with definite and indefinite modified DPs (mean and SD)

\begin{tabular}{lcccc}
\multicolumn{1}{c}{ Group } & PP def /4 & PP indef/4 & RC def/4 & RC indef/4 \\
2L1 & 1.69 & 1.75 & 2 & 1.69 \\
5-year olds & $(1.30)$ & $(1.13)$ & $(1.11)$ & $(0.79)$ \\
L1 & 1.5 & 1.44 & 1.63 & 1.69 \\
5-year olds & $(0.82)$ & $(1.15)$ & $(1.26)$ & $(0.87)$ \\
2L1 & 1.63 & 1.88 & 1.69 & 1.88 \\
7-year olds & $(1.02)$ & $(1.02)$ & $(1.19)$ & $(1.26)$ \\
L1 & 2.44 & 2.63 & 2.5 & 2.56 \\
7-year olds & $(1.41)$ & $(1.45)$ & $(1.21)$ & $(1.15)$ \\
Adults & 3.67 & 3.67 & 4.00 & 3.83 \\
& $(.52)$ & $(.52)$ & $(.00)$ & $(.41)$
\end{tabular}


The acquisition of recursively embedded noun modifiers in Romanian by Hungarian-Romanian bilinguals 73

\subsubsection{Error analysis}

When children did not choose the recursive option they either went for the conjunctive reading or for "other" responses. The conjunctive responses show a different pattern with the $\mathrm{L} 1$ and the $2 \mathrm{~L} 1$ participants. At age 5, the bilinguals gave fewer conjunctive responses $(23.05 \% ; \mathrm{n}=59)$ than the monolinguals $(38.7 \% ; \mathrm{n}=99)$ but more "other" responses: $30.9 \%(\mathrm{n}=79)$ vs. $22.7 \%(\mathrm{n}=57)$. At age 7 , the rate of conjunctive responses increases with the bilingual children $(47.27 \% ; n=121)$, and it decreases with the monolinguals $(20.7 \% ; n=53)$.

In order to test whether the difference between the two groups was significant, an independent t-test at the $\alpha=.05$ level was conducted. Overall conjunctive responses in the $2 \mathrm{~L} 1$ group $(\mathrm{M}=7.56, \mathrm{SD}=4.44)$ differed significantly from those in the L1 group $(\mathrm{M}=$ $3.31, \mathrm{SD}=3.16), \mathrm{t}(27)=-3.12, p<.05$. The 7 -year-old bilingual children gave significantly more conjunctive responses than the 7-year-old monolinguals.

These results are summarized in Table 4.

Table 4. Recursive, conjunctive and "other" responses overall (mean and SD) per groups

$\begin{array}{ccccc}\text { Age group } & \text { 2L1/L1 } & \text { Recursive } & \text { Conjunctive } & \text { "Other" } \\ \text { 5-year-olds } & \text { 2L1 } & 7.1(3.05) & 3.69(2.65) & 4.94(3.17) \\ & \text { L1 } & 6.25(3.02) & 6.19(2.74) & 3.56(1.93) \\ \text { 7-year-olds } & \text { 2L1 } & 7.1(3.96) & 7.56(4.44) & 1.37(1.89) \\ & \text { L1 } & 10.12(2.63) & 3.31(3.16) & 2.56(2.63) \\ \text { Adults } & & 15.16(.99) & .66(.82) & .33(.52)\end{array}$

The data in Table 4 indicate that the 5-year-old bilinguals gave the highest number of "other" responses. Actually, as can be seen in Figure 7, the comparison of the responses given by the 5-year-old and by the 7-year-old monolinguals reveals a decrease in both the number of conjunctive and of "other" responses; the decrease with respect to "other" responses, however, is less spectacular. For the 2L1 group, the comparison reveals a significant increase in the number of conjunctive responses and a significant decrease in the number of "other" responses given by the 5-year-olds and by the 7-year-olds.

We then compared the rate of conjunctive responses per condition: PP and relative clause modifiers. Adults gave a conjunctive interpretation in $6.25 \%$ of cases in the PP condition and $2.08 \%$ of cases in the relative clause condition.

The 5-year-old bilinguals assigned a conjunctive interpretation to complex DPs with recursively embedded PP modifiers $21.9 \%(n=28)$ of the time, and $24.22 \%(n=31)$ to complex DPs with embedded relative clause modifiers. The 5-year-old monolingual group gave a similar number of conjunctive responses in the two conditions: $39.06 \%$ $(\mathrm{n}=50)$ in the PP condition and $38.3 \%(\mathrm{n}=49)$ in the relative clause condition. A two-way ANOVA was conducted on the effect of group and condition on the number of conjunctive responses. There was a significant main effect only for group, $F(1,60)=$ $10.67, p=.001$, i.e. the difference between the number of conjunctive responses given by the 5-year-old bilinguals was significantly lower than the number of conjunctive responses given by the 5-year-old monolinguals. There was no main effect of condition 
$(\mathrm{F}(1,60)=.03, p>.05)$ and no significant interaction between group and condition $(\mathrm{F}(1,60)=.11, p>.05)$.

The 7-year-old bilinguals gave a similar number of conjunctive responses in the two conditions: $46.87 \%(n=60)$ in the PP condition and $47.66 \%(n=61)$ in the relative clause condition. The 7-year-old monolinguals gave fewer conjunctive responses in both conditions: $21.88 \%(\mathrm{n}=28)$ in the PP condition and $19.53 \%(\mathrm{n}=25)$ in the relative clause condition. A two-way ANOVA was conducted on the effect of group and condition on the number of conjunctive responses. There was a significant main effect only for group, $\mathrm{F}(1,60)=17.88, p=.00$, i.e. the difference between the number of conjunctive responses given by the 7-year-old bilinguals was significantly higher than the number of conjunctive responses given by the 7-year-old monolinguals. There was no main effect of condition $(\mathrm{F}(1,60)=.02, p>.05)$ and no significant interaction between group and condition $(\mathrm{F}(1,60)=.06, p>.05)$.

The results are summarized in Table 5:

Table 5. Conjunctive responses (mean and SD) in the PP and relative clause conditions

$\begin{array}{cccc}\text { Group } & \text { Age } & \text { PP /8 } & \text { Relative clause /8 } \\ \text { 5-year-olds } & \text { 2L1 } & 1.75(1.39) & 1.94(1.53) \\ & \text { L1 } & 3.13(1.36) & 3.06(1.81) \\ \text { 7-year-olds } & \text { 2L1 } & 3.75(2.05) & 3.6(3.81) \\ & \text { L1 } & 1.75(1.81) & 1.56(1.41) \\ \text { Adults } & & .05(.55) & .17(.41)\end{array}$

The last step in our analysis targeted one lexical error which was found with all the four groups of children: preposition change. In some responses on was interpreted as under, in other responses on was interpreted as next to and, less frequently, next to was interpreted as under. Interestingly, the highest number of preposition changes was produced by the 7-year-old bilinguals. Within the monolingual group, no difference was observed between the 5-year-olds and the 7-year-olds. But the 7-year-old bilinguals produced a higher number of responses with preposition change than the 5-year-olds. The data are summarized in Table 6:

Table 6. Preposition change across groups

$\begin{array}{cccc}\text { 5-year-old /L1 } & 5 \text {-year-old/2L1 } & 7 \text {-year-old/L1 } & \text { 7-year-old/2L1 } \\ 35 & 39 & 33 & \mathbf{5 1}\end{array}$

Preposition change is subject to individual variation. In the 7-year-old bilingual group, for example, it ranges from 0 to 8 . In the 7-year-old monolingual group, it ranges in between 0 to 6 , but 8 out of 16 children did not make this error at all.

The analysis of the pattern of "other" responses is similar in $\mathrm{L} 1$ and in $2 \mathrm{~L} 1$. When the test sentence included PP modifiers headed by $p e$ 'on', i.e. $X$ pe $Y$ pe Z, the most frequently encountered type of "other" response was * $\mathrm{Z}$ pe $\mathrm{X}$ pe $\mathrm{Y}$. For example, for the test sentence Show me the chicken on the cat on the pig, which required the recursive array in Figure $6 \mathrm{a}$, both the monolinguals and the bilinguals preferentially provided an 
array like the one in Figure 6b. The most frequently encountered pattern of the "other" responses to these prompts was like the one in $6 \mathrm{~b}$ (instead of the recursive array in 6a).

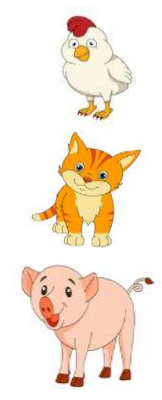

Figure 6a. Recursive response



Figure 6b. "Other" response

"Other" responses to Show me the chicken (that is) next to the cat (that is) next to the pig included arrays like the one in 7 :
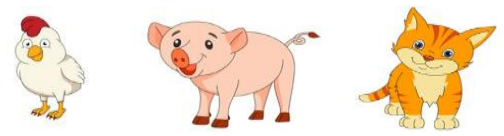

Figure 7. "Other" array in response to Show me the chicken next to the cat next to the pig.

\subsection{Discussion}

The first question which was addressed in this study was whether the acquisition of recursively embedded noun modifiers in Romanian by Hungarian-Romanian bilingual children proceeds along the same steps and at similar speed as in L1 acquisition. The data show that, indeed, the acquisition of recursively embedded nominal modifiers proceeds in the same order in the two acquisition contexts. Both the bilingual and the monolingual children go through a stage when they do not always assign a recursive interpretation to complex DPs with embedded modifiers. The results for 2L1 and L1 Romanian support Roeper's (2011:65) view according to which direct recursion is the acquisition default. A "conjunctive first" stage has been reported for L1 English (Sevcenco et al. 2017), L1 Hungarian (Tóth 2016, 2017) and L1 Romanian (Sevcenco \& Avram 2018). The present study offers evidence that recursive structures are still interpreted as conjunctive in both L1 and 2L1 Romanian at age 7.

The data also show that the acquisition of recursively embedded nominal modifiers is delayed in both L1 and 2L1 Romanian, in accordance with previous studies. At age 7, neither Romanian monolinguals nor Hungarian-Romanian simultaneous bilinguals understand these structures in an adult-like manner. Previous studies suggested that recursive relative clause modification is acquired earlier than PP noun modification. For English, Sevcenco et al. (2017) present experimental data which show that there is a head start in the comprehension of recursive structures with relative clauses over those with PPs. No similar advantage for recursive readings with full clausal modification (relative 
clause) over the reduced one (PP) was found in either L1 or 2L1 Romanian, in accordance with results reported in previous L1 studies (Sevcenco \& Avram 2016, 2018).

Both groups were equally insensitive to definiteness as a cue to recursive readings. The results did not differ in the two groups, not even when the second modified noun was indefinite, i.e. when the interpretation was ambiguous between a conjunctive and a recursive interpretation. Importantly, these results cannot indicate a delay in the acquisition of the definiteness feature in general. Ticio \& Avram (2015), Avram \& Tomescu $(2016,2020)$, for example, provide evidence that both monolingual speakers of Romanian and Hungarian-Romanian bilinguals are sensitive to the role of definiteness in differential object marking before age 3 .

These data offer a picture in which $2 \mathrm{~L} 1$ and $\mathrm{L} 1$ acquisition proceed along the same steps, from conjunctive to recursive interpretation, with no difference between PP and relative clause modification, in support of the unitary language system hypothesis (Meisel 1989, de Houwer 1990). The acquisition of recursive noun modifiers is indeed delayed, but it is delayed in both $\mathrm{L} 1$ and $2 \mathrm{~L} 1$, irrespective of modification type: locative PP or subject relative clause.

The overall delay in L1 and 2L1 Romanian can be accounted for in terms of derivational complexity, i.e. in terms of third factors, in line with several previous studies. Sevcenco \& Avram (2018) suggest that the conjunctive interpretation is a strategy which children resort to in order to integrate the required adjuncts in the overall configuration while avoiding a second embedding across intermediate phasal domains. During early stages of acquisition, nominal modifiers are iteratively stacked onto the first DP, without interfering with the truth value of the whole expression (Roeper \& Oseki 2018). The conjunction structure which children choose to the detriment of the recursive one involves finding, projecting and labeling the highest modified DP and relating the DP to two non-embedded adjuncts:



(from Sevcenco and Avram 2018: 275)

Assigning the correct recursive interpretation is more computational cost demanding; it requires Minimal Search Extended steps (i.e. finding identical heads of XPs across phase transfer sites) (Sevcenco et al. 2017). For example, in the case of a DP modified by recursive PPs, like the one in (16), the projected highest DP (porcul 'the pig') must be assigned a label. Next, the phasal domain whose head is the preposition $d e$ 'de' has to be identified. Inside this domain, an intermediate DP has to be identified and labeled (calul 'the horse'). Additionally, one more phasal domain will have to be posited as an adjunct to this second (intermediate DP): 
(16) porcul de pe calul de pe câine pig-the of on horse-the of on dog 'the pig on the horse on the dog'

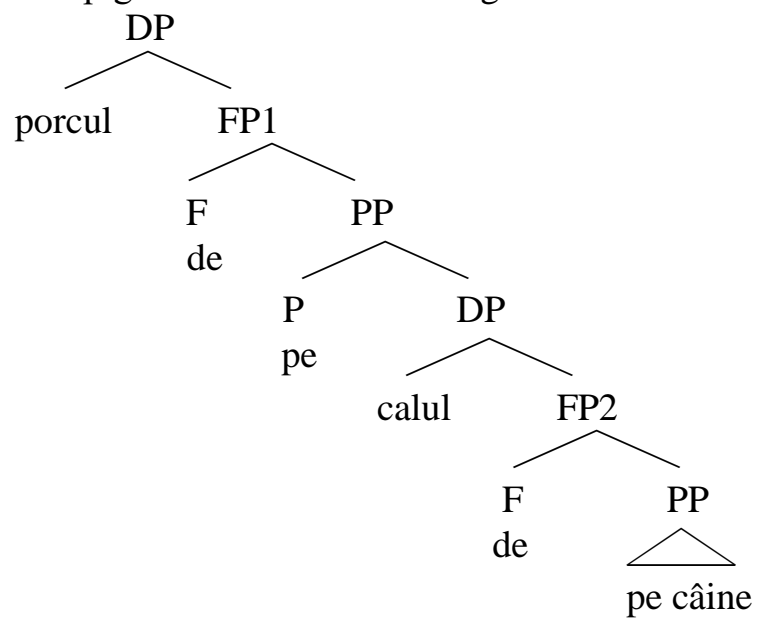

(Sevcenco \& Avram 2018: 275)

Several additional findings, however, suggest that there is a developmental difference between monolinguals and simultaneous bilinguals, i.e. they go along the same path, but at a different speed. The results showed that the rate of recursive responses increased significantly from age 5 to age 7 only with the monolinguals. With the simultaneous bilinguals, there was no progress from age 5 to age 7 . In spite of the overall similarity, the lack of a significant increase in recursive answers with the bilinguals suggests that there is a slight delay in the $2 \mathrm{~L} 1$ acquisition of recursive nominal modifiers. In L1 there is a jump point with respect to recursive responses from age 5 to age 7 , which is not replicated in $2 \mathrm{~L} 1$. These findings show that when the acquisition of a particular computationally complex structure is delayed in L1, the delay is more significant in $2 \mathrm{~L} 1$.

This view is reinforced by the comparison of the response pattern found in the four groups. The response pattern of the 7-year-old bilinguals is similar to the one in the group of 5-year-old monolinguals: recursive and conjunctive interpretations are almost equally assigned to complex DPs with embedded modifiers. The 7-year-old monolinguals, on the other hand, gave significantly more recursive responses than conjunctive ones and 4 children in this group gave $100 \%$ recursive answers across conditions. The 5-year-old bilinguals differ from all the other groups in that they gave a high number of "other" responses and their rate of conjunctive answers is lower.

\begin{tabular}{|ll|}
\hline 5-year-old monolinguals & recursive $(39.1 \%)=$ conjunctive $(38.7 \%)$ \\
7-year-old monolinguals & recursive $(61.8 \%)>$ conjunctive $(20.7 \%)$ \\
5-year-old bilinguals & recursive $(44.53 \%)>$ other $(30.9 \%>$ conjunctive $(23.05 \%)$ \\
7-year-old bilinguals & recursive $(44.14 \%)=$ conjunctive $(47.27 \%)$ \\
\hline
\end{tabular}


At first sight, the high number of "other" responses with the 5-year-old bilinguals could indicate that they might have had problems solving the task. But such an account is challenged by the general view according to which bilinguals are at an advantage when required to perform on spatial problems, or on problem-solving abilities (see the overview in Müller 2017). An alternative explanation could be that their knowledge of Romanian in general lags behind. This is supported by the fact that in the 5-year-old bilingual group, "other" responses range in between $0-9$, with 4 children giving 9 (out of 16) such responses. For the age-matched monolinguals, the number of "other" responses ranges in between $0-6$, with only one child giving 6 "other" responses.

That the bilinguals may be lagging behind is also confirmed by the high number of preposition change errors, which target lexical prepositions. Such preposition changes are also attested in L1 Romanian, but at age 7 an increase was attested only with the bilingual group (from 39 to 51). A closer look at the "other" and preposition change response in 2L1 could shed some light on this issue, which is directly related to the second question which we addressed, i.e. whether the acquisition of recursively embedded noun modifiers is affected by cross-linguistic interference effects. We argue that such effects exist, even though they may be weak and may not reflect directly on the recursive answers given by the bilingual children. These effects could account for the slight delay observed with the Hungarian-Romanian bilinguals. As shown in section 2, the word order of the constituents inside complex DPs with recursively embedded PP and relative clause noun modifiers is different in the two languages. In Romanian, modification is uniformly rightbranching. In Hungarian, PP modification is left-branching, while relative clause modification is right-branching; but even in these relative clause configurations, where the modifiers are in postnominal position, the order of the recursive modifiers is different from the one in Romanian (see examples 7 and 8 above). The difference in directionality and word order may favour cross-linguistic interference effects. The bilingual child could (randomly) apply the analysis of a grammatical structure $x$ as expressed in Hungarian when interpreting a Romanian structure, possibly more often when there is a superficial similarity between the two (as is the case with relative clause modification, which is right-branching in both languages).

For example, in our task, the response to the prompt Show me the pig next to the chicken next to the cat should have been the recursive array in Figure 2, repeated here for convenience as Figure 8:


Figure 8. Example of a recursive response to

Show me the pig next to the chicken next to the cat.

If the bilingual child applies the analysis of the similar structure available in Hungarian (17a and b), i.e. the order in recursively embedded postpositional phrases adjectivized by the suffix $-i$ (see also 7 a above) or in embedded postpositional phrases with levö participial structures (see also $7 \mathrm{~b}$ above) the array will look like the one in Figure 9. 
a. a macska mellet-i csirke mellett-i disznó the cat near ADJ chicken near ADJ pig 'the pig next to the chicken next to the cat'

b. a macska mellett levő csirke mellet levő disznó the cat near being-PRT chicken near being-PRT pig 'the pig next to a chicken next to a cat'

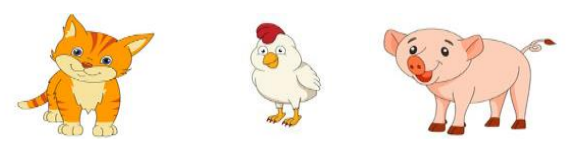

Figure 9. Example of response to Show me the pig next to the chicken next to the cat. reflecting cross-linguistic interference effects

If the test sentence is analyzed starting from the word order in structures with a postnominal finite relative clause and a prenominal participial structure as in (18a) (see also 8a above), or with a postnominal finite relative clause and an embedded postpositional phrase adjectivized by $-i$, as in (18b) (see also $8 \mathrm{~b}$ above), the array might look like the one in Figure 10.
a.
a disznó amelyik a macska mellett-i csirke mellett van the pig which the cat near ADJ chicken near is 'the pig which is next to the chicken which is next to the cat'
b. a disznó amelyik a macska mellett levő csirke the pig which the cat near being-PRT chicken mellett van
near is
'the pig which is next to the chicken which is next to the cat'

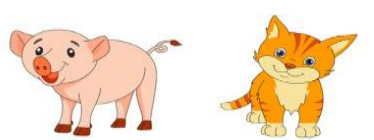

Figure 10. Example of response to Show me the pig (that is) next to the chicken (that is) next to the cat reflecting cross-linguistic interference effects

With test sentences which contained the preposition $p e$ 'on' cross-linguistic interference effects could, in principle, have resulted in either "other" responses but also in recursive responses with preposition change. The prompt Show me the chicken (that is) on the cat (that is) on the pig required a recursive array as in Figure 11a. But if the bilingual child analyzed the test sentence with the order in recursively embedded postpositional phrases adjectivized by the suffix $-i$ (as in $7 \mathrm{a}$ and 18a) or with the order in embedded postpositional phrases with levö participial structures (as in $7 \mathrm{~b}$ and $18 \mathrm{~b}$ ) the arrays might look like the one in Figure $11 \mathrm{~b}$, which we coded as preposition change (pe 'on' seemed to be interpreted as $s u b$ 'under'). 
If the bilingual child analyzed the same prompt starting from the word order in structures with relative clause modification, the array would be the one in Figure 11c, coded as "other".

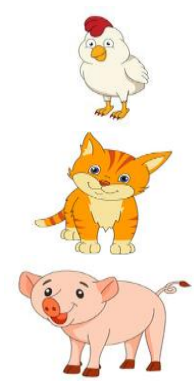

Fig. 11a. Recursive response
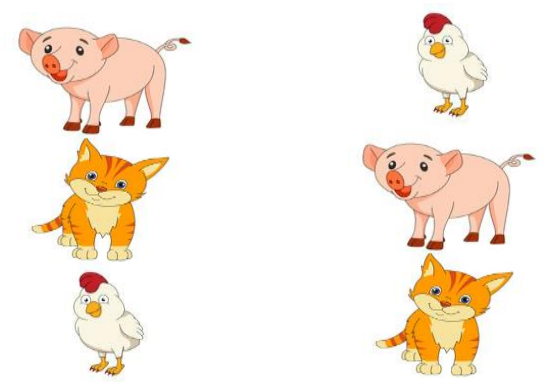

Fig. 11b-c. 2L1: Responses to Show me the chicken (that is) on the cat (that is) on the pig reflecting cross-linguistic interference effects

Summing up, if the bilingual child applied the analysis of the equivalent structures in Hungarian, the response could, in principle, be of the "other" type with lângă 'next to' test sentences. When the prompt contained the preposition pe 'on', the response could have been of the "other" or of the preposition change type. The 5-year-old bilinguals gave a high number of "other" responses $(\mathrm{n}=79)$, higher than the 5-year-old monolinguals $(\mathrm{n}=57)$. The "other" responses given by the bilinguals were more numerous because they may have been favoured, besides the children's relatively low overall proficiency in Romanian, by cross-linguistic interference effects. The number of responses like the ones in $11 \mathrm{c}$ and 10, which reflect an analysis based on relative clause modification in Hungarian, is higher with the 5-year-old bilinguals $(n=10)$ than with the 7 -year-old ones $(\mathrm{n}=1)$. Possible early cross-linguistic effects involve rather an analysis of the Romanian data starting from the right-branching modification structure in Hungarian, i.e. the one in which directionality is similar to noun modification in Romanian.

The overall number of "other" responses is lower with the 7-year-old bilinguals $(\mathrm{n}=22)$. But with this older group there is an increase in preposition change responses $(n=51)$. And over half of these responses $(n=27)$ are in relation to the preposition on, i.e. they might be the result of cross-linguistic interference effects. It is not implausible to assume that in this age group the distribution of cross-linguistic interference effects on complex PPs with pe 'on' resulted less frequently in "other" responses and more frequently in responses which look like preposition change ones (as in Figure 11b). There seems to be a trade-off between "other" and preposition change responses from age 5 to age 7, i.e. a possible shift from applying mainly the relative clause modification analysis to also applying the PP modification analysis.

In spite of the fact that the group of bilingual children in our study is relatively small, we believe that the delay observed in the $2 \mathrm{Ll}$ acquisition of recursively embedded noun modifiers cannot be fully dissociated from possible cross-linguistic interference effects, which may additionally hinder the recursive interpretation of complex DPs with recursively embedded PP and relative clause noun modifiers. 
One has to mention that our results only allow us to assume that there is a possible weak cross-linguistic effect. This is because of the overlap between the "other" responses given by the monolinguals and those which could reflect cross-linguistic interference effects in 2L1. Further studies, looking at a pair of languages which do not differ with respect to directionality and at a pair of languages which differ with respect to directionality in both types of modifiers investigated here (locative PP and subject relative clauses) could shed further light on this issue.

\section{Conclusions}

Our study investigated the acquisition of recursively embedded noun modifiers (locative PPs and subject relative clauses) in Romanian by Hungarian-Romanian bilingual children, focusing on the interplay between core syntax, language specific properties and cross-linguistic interference effects. The results showed that simultaneous bilinguals go through the same acquisition stages as monolinguals. We found no significant quantitative differences between bilinguals and monolinguals with respect to the recursive comprehension of complex DPs with multiple embedded modifiers. Both monolingual and bilingual children found it equally difficult to use language specific cues, such as those provided by the definiteness feature, in their comprehension of complex DPs with recursive modifiers. In this respect our findings support the unitary language system hypothesis. But our results also reveal a slight developmental difference between simultaneous bilingual children and age-matched monolinguals. We found no significant progress from age 5 to age 7 with simultaneous bilingual children, who seem to be staying in an "avoid recursive interpretation" stage longer. We suggested that this delay can be accounted for in terms of the computational complexity involved in the structures investigated, overall knowledge of Romanian and cross-linguistic interference effects. Interference may be favoured by derivational complexity and, possibly, reduced input. On this view, the observed delay follows naturally from the interaction between language specific properties, computational complexity and dual linguistic input.

\section{References}

Alegre, M.A. \& Gordon, P. 1996. Red rats eater exposes recursion in children's word formation. Cognition 60: $65-82$.

Avram, L. \& Tomescu, V. 2016. Selective vulnerability: Differential object marking in 2L1 Romanian. Paper presented at Workshop on the Acquisition of Differential Object Marking, 9-10 December 2016, INALCO, Paris.

Avram, L. \& Tomescu, V. 2020. Differential object marking in simultaneous Hungarian-Romanian bilinguals. In A. Mardale \& S. Montrul (eds.), The Acquisition of Differential Object Marking, 77104. Amsterdam/Philadelphia: John Benjamins.

Bialystok, E. 2009. Bilingualism: The good, the bad, and the indifferent. Bilingualism: Language and Cognition 1: 3-11.

Bleotu, A. C. 2020. A peek into recursion and coordination in child Romanian. Ms. ISDS, University of Bucharest.

Chomsky, N. 2013. Problems of projection. Lingua 130: 33-49. 
Chomsky,N. 2014. Minimal recursion: Exploring the prospects. In T. Roeper \& M. Speas (eds.), Recursion: Complexity in Cognition, 1-17. New York: Springer.

Hauser, M. D., Chomsky, N. \& Fitch, W.T. 2002. The faculty of language: What it is, who has it and how did it evolve? Science 298: 1569-1579.

De Houwer, A. 1990. The Acquisition of Two Languages from Birth: A Case Study. Cambridge: Cambridge University Press.

Giurgea, I. 2015. Romanian adnominal locative PPs and argument structure. https://ling.auf.net/ling buzz/002335.

Limbach, M. \& Adone, D. 2010. Language acquisition of recursive possessives in English. In K. Franich, K. M. Iserman, \& L. L. Keil (Eds.), BUCLD 34. Proceedings of the 34th Annual Boston University Conference on Language Development, 281-290. Somerville, MA: Cascadilla Press.

Meisel, J. M. 1989. Early differentiation of languages in bilingual children. In K. Hyltenstam \& L. K. Obler (eds.), Bilingualism across the Lifespan: Aspects of Acquisition, Maturity and Loss, 13-40. Cambridge: Cambridge University Press.

Meisel, J. M. 2011. First and Second Language Acquisition. Parallels and Differences. Cambridge: Cambridge University Press.

Müller, N. 2017. Different sources of delay and acceleration in early child bilingualism. Zeitschrift für Sprachwissenschaft 1: 7-30.

Paradis, J. \& Genesee, F. 1996. Syntactic acquisition in bilingual children: Autonomous or interdependent? Studies in Second Language Acquisition 18: 1-25.

Pérez-Leroux, A. T., Castilla-Earls, A. P, Béjar, S. \& Massam, D. 2012. Elmo's sister's ball: The problem of acquiring nominal recursion. Language Acquisition 19: 301-311.

Pérez-Leroux, A. T., Peterson, T., Castilla-Earls, A. P., Massam, D. \& Béjar, S. 2015. Nominal reference, modification and the acquisition of complex NPs. Ms. University of Toronto, University of Arizona, SUNY/Fredonia.

Pérez-Leroux, A. T., Pettibone, E. \& Castilla-Earls, A. P. 2017. Down two steps: Are bilinguals delayed in the acquisition of recursively embedded PPs? Matraga 41: 393-416.

Pettibone, E., Klassen, G. \& Pérez-Leroux, A.T. 2016. Bilingual effects in recursive noun phrases. Paper presented at A Complexity in Acquisition Workshop, 25 May 2016, University of Toronto.

Pîrvulescu, M., Pérez-Leroux, A.-T., Y. Roberge, \& Strik, N. 2014. Bilingual effects: Exploring object omission in pronominal languages. Bilingualism: Language and Cognition 17 (3): 495-510.

Roberge, Y., Pérez-Leroux, A.T. \& Frolova, A. 2018. On recursive modification in child L1 French. Languages 3 (1). https://doi.org/10.3390/languages3010006.

Roeper, T. 2010. The minimalist microscope: How and where interface principles guide acquisition. In J. Chandlee, M. Franchini, S. Lord \& G. M. Rheiner (eds.), Proceedings of the $33^{\text {rd }}$ Annual Boston University Conference on Language Development, 24-48. Somerville, MA: Cascadilla Press.

Roeper, T. 2011. The acquisition of recursion: How formalism articulates the child's path. Biolinguistics 5 (1-2): 57-86.

Roeper, T. \& Oseki, Y. 2018. Recursion in the acquisition path for hierarchical syntactic structure. In L. Amaral, M. Maia, A. Nevins, \& T. Roeper (eds.), Recursion across Domains, 267-278. Cambridge: Cambridge University Press.

Sevcenco, A. \& Avram, L. 2016. Computational complexity and the interpretation of recursive structures in child Romanian. Paper presented at Workshop on Computational Complexity in Language Acquisition, 29 November 2016, University of Cambridge.

Sevcenco, A. \& Avram, L. 2018. On the comprehension of recursive nominal modifiers in child Romanian. In A. Gavarró (ed.), On the Acquisition of the Syntax of Romance, 259-278. Amsterdam/Philadelphia: John Benjamins.

Sevcenco, A., Roeper, T. \& Pearson-Zurer, B. 2017. The acquisition of recursive locative PPs and relative clauses in child English. In H. Demirdache, J. Choi, O. Lungu \& L. Voeltzel (eds.), Language Acquisition at the Interfaces: Proceedings of GALA 2015, 287-301. Newcastle upon Tyne: Cambridge Scholars Publishing.

Terunuma, A., Isobe, M., Nakajima, M., Okabe, R., Inada, S., Inokuma, S. \& Nakato, T. 2017. Acquisition of recursive possessives and locatives within DPs in Japanese. In M. LaMendola \& J. Scott (eds.), Proceedings of the $41^{\text {st }}$ Annual Boston University Conference on Language Development, 626-636. Somerville, MA: Cascadilla Press. 
The acquisition of recursively embedded noun modifiers in Romanian by Hungarian-Romanian bilinguals 83

Ticio, E. \& Avram, L. 2015. The acquisition of differential object marking in Spanish and Romanian: Semantic scales or semantic features? Revue roumaine de linguistique, special issue on The Acquisition of Differential Object Marking in L1 Acquisition LX (4): 383-402.

Tóth, A. 2017. The role of functional heads in Hungarian PP recursion. Paper presented at $13^{\text {th }}$ International Conference on the Structures of Hungarian (ICSH 13), June 2017, Budapest.

Tóth, A., É.Kiss, K. \& Roeper, T. 2016. The role of the visible functional head in the interpretation of recursion. Paper presented at GALANA 7, September 2016, University of Illinois at UrbanaChampaign.

Tsimpli, I. M. 2014. Early, late or very late? Timing acquisition and bilingualism. Linguistic Approaches to Bilingualism 4 (3): 283-313.

Unsworth, S. 2014. Comparing the role of input in bilingual acquisition across domains. In T. Grüter \& J. Paradis (eds.), Input and Experience in Bilingual Development, 181-201. Amsterdam/Philadelphia: John Benjamins.

\section{Appendix. Test sentences}

\section{Recursive PPs with indefinite DP}

1. Arată-mi un pui de lângă un cal de lângă un porc.

show me a chicken of near a horse of near a pig

'Show me a chicken next to a horse next to a pig'.

2. Arăă-mi un câine de lângă un pui de lângă o pisică

show me a dog of near a chicken of near a cat

'Show me a dog next to a chicken next to a cat'.

3. Arată-mi un porc de pe o pisică de pe un cal. show me a pig of on a cat of on a horse 'Show me a pig on a cat on a horse'.

4. Arată-mi un cal de pe o pisică de pe un câine show me a horse of on a cat of on a dog 'Show me a horse on a cat on a dog'.

\section{Recursive PPs with definite DP}

5. Arată-mi pisica de lângă calul de lângă pui. show me cat-the of near horse-the of near chicken

'Show me the cat next to the horse next to the chicken'.

6. Arată-mi câinele de lângă pisica de lângă cal show me dog-the of near cat-the of near horse 'Show me the dog next to the cat next to the horse'.

7. Arată-mi puiul de pe porcul de pe cal show me chicken-the of on pig-the of on horse 'Show me the chicken on the pig on the horse'.

8. Arată-mi puiul de pe câinele de pe porc. show me chicken-the of on dog-the of on pig 'Show me the chicken on the dog on the pig'. 


\section{Recursive relative clauses with indefinite DP}

9. Arată-mi un porc care este lângă un pui care este lângă o pisică show me a pig that is near a chicken that is near a cat 'Show me a pig that is next to a chicken that is next to a cat'.

10. Arată-mi un pui care este lângă un cal care este lângă un câine show me a chicken that is near a horse that is near a dog 'Show me a chicken that is near a horse that is near a dog'.

11. Arată-mi o pisică care este pe un cal care este pe un porc. show me a cat that is on a horse that is on a pig 'Show me a cat that is on a horse that is on a pig'.

12. Arată-mi un cal care este pe un porc care este pe un pui. show me a horse that is on a pig that is on a chicken 'Show me a horse that is on a pig that is on a chicken'.

\section{Recursive relative clauses with definite DP}

13. Arată-mi calul care este lângă pisica care este lângă porc. show me horse-the that is near cat-the that is near pig 'Show me the horse that is next to the cat that is next to the pig'.

14. Arată-mi porcul care este lângă calul care este lângă câine. show me pig-the that is near horse-the that is near dog 'Show me the pig that is next to the horse that is next to the dog'.

15. Arată-mi puiul care este pe porcul care este pe cal show me chicken-the that is on pig-the that is on horse 'Show me the chicken that is on the pig that is on the horse'.

16. Arată-mi câinele care este pe porcul care este pe pui. show me dog-the that is on pig-the that is on chicken 'Show me the dog that is on the pig that is on the chicken'. 